\title{
Design and construction of the Kingsferry lifting bridge, Isle of Sheppey
}

by

\author{
J. K. Anderson, M.A.(Cantab.), M.I.C.E. \\ and
}

C. D. Brown, B.Sc., A.M.I.C.E.

Mr G. A. V. Russell wrote that while the layout of the lifting mechanism selected hid the working parts and thus made the completed structure look 'clean', it did result in an inaccessible location for the winch units and pulleys. He wondered if the alternative of overhead drives was considered by the Authors as it would appear to offer greater simplicity and accessibility. The tower cross-ties could, with appropriate modification, carry the winch unit for each end of the lifting platform and if a mechanical tie was preferred this could be carried between the hoist motors or winch shafts on a longitudinal beam extending between the tower cross-ties.

Mr J. H. Ainsley (Imperial College) wrote that in $\$ 28$ the Authors gave a detailed description of the ropes used to suspend the counter-balances, but did not mention that all six ropes in each batch were laid up the same way. Mr Ainsley said that when he visited the Kingsferry bridge recently, while showing him the guide mechanism for the counterweights, the maintenance technician had remarked that the guide shoes on the weights wore unevenly, one side needing replacement before the other. The technician thought that this was due to the ropes all being laid the same way, so causing an overall torsion on the counterweight boxes.

73. Did the Authors think this a sound view, and, if so, would the use of three right- and three left-hand lay ropes in each set have solved the problem without raising further difficulties? Furthermore if all four sets were laid in the same way would the resulting torsion on the lifting span add sensibly to the wear on the span guide shoes, and, if so, could anything be done to alleviate this?

Mr A. K. Chattopadhyay $†$ (Freeman, Fox \& Partners) wrote that he was particularly interested in the design of the steel bridge deck. The design could, however, have been better appreciated had the Authors stated design data, viz. loadings, quality of steel, and stresses used. It would also have been informative to know whether the composite deck was designed according to a foreign code of practice, and if so, which code, especially since there is no British Code.

75. . He wondered if the Authors had used or considered using different qualities of steel on the main girders to balance some of the unequal loadings on the rail and road side of the bridge. This would have been particularly beneficial in the economy

* Proc. Instn civ. Engrs, vol. 28, August 1964, pp. 449-470.

$\dagger$ We regret that $\mathrm{Mr}$ Chattopadhyay died before publication of this contribution. 
of the scheme had this reduced the weight of the lifting span. In $\S 23$, mention was made of the difficulty of welding the main girders, due to thick flanges. Could the Authors give an idea of the sectional properties of these, which according to them were considered unsuitable for welding.

76. He noticed that plain rolled steel sections had been used compositely with reinforced concrete deck slab for the stringers on the lifting span. He thought that better use of composite construction could have been achieved by using unequal flanges. This could be readily effected by adding suitable cover plates to the tension flange of a lighter section.

77. The type of the shear connectors used was not clearly mentioned, but from the details of Fig. 6, section B-B, of the Paper, he assumed they were the rigid type, similar to those used in the cross girders of the approach span. Design rules for shear connectors were given in clauses 13.1,13.2, and 13.3 of German Standard DIN 1078, ${ }^{1}$ which required the design of the connectors to be based on the shear force diagram. They also gave the modifications necessary for creep, shrinkage, and temperature stresses. In German practice where rigid connectors were used, it was usually necessary to place a special large connector at the ends of the beams. Similar end connectors were also required by clause 7.35 of DIN $4239,{ }^{2}$ the German Code for Composite Construction in buildings. It might not be out of place to describe the composite type of shear connectors (Fig. 13) widely recommended at the present

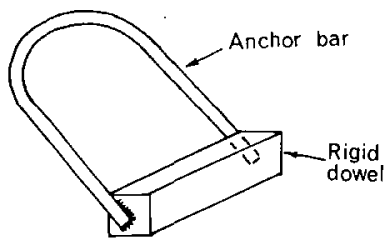

Fig. 13: TYPICAL COMPOSITE TYPE SHEAR CONNECTOR

time. They consisted of a rigid connector with bar-type anchors and had been shown by Professor Graf of Germany to be most efficient and this had been confirmed by a recent Russian report. Such connectors combined the advantages of the rigid type connectors and the bond-type of connecting anchors. However, this arrangement would need shear connectors at the ends of the road stringers. He would like to have the Authors' comments regarding their omission of shear connectors at the ends of the stringers (Fig. 6, section B-B). Perhaps they would also state whether the shear connectors were omitted at the ends of the cross girders of the approach spans.

78. Finally, he asked the Authors to give some idea of the magnitude of precambering and setting in fabrication as mentioned in $\$ 37$ and the method adopted in achieving them.

The Authors, in reply, stated that overhead drives using tower cross-ties as suggested by Mr G. A. V. Russell were not considered. An underground mechanical tie, making use of the cable tunnel, was considered, but it was thought that this would have been complicated compared with the simple electrical ties carried through the cable tunnel.

80. In relation to the bridge ropes, $\mathrm{Mr} \mathrm{J}$. H. Ainsley was correct in stating that the ropes were all laid up the same way and that this caused a small overall torsion. It would perhaps have been better to use right-hand and left-hand lay ropes alternatively. However, if locked coil ropes were used in any future design these could be laid up in balanced construction in order to produce a zero residual torque design for each rope. The question of wear on guide shoes was not an important matter and direct bearing of the guide shoes on the guide rails ensured accurate positioning of the span and counterweights. 
81. The design loadings for the bridge, requested by Mr A. K. Chattopadhyay, were as specified in B.S.153, part 3A. The highway was checked for HB. loading and the railway was designed for type RB loading at $6 \mathrm{rev} / \mathrm{sec}$.

82. Steel generally was to B.S.15 with the steel for tension flanges of welded girders to B.S.2762 N.D. II Class A. The composite deck design was generally in accordance with the standard specification of the American Association of State Highway Officials. The use of different qualities of steel on the main girders was considered, but this did not appear to offer any substantial financial advantage and might have introduced delays. The riveted flanges were up to $3 \frac{3}{8}$ in. thick. They were not considered unsuitable for welding, but the successive flange curtailment made possible by riveted construction led to overall economy.

83. In relation to the use of plain rolled steel sections as stringers for composite construction, although this was more wasteful in basic material than using fabricated stringers with unequal flanges, they were economical, bearing in mind the lower cost of rolled steel sections compared with fabricated sections.

84. Rigid type shear connectors were used with tie-down hoops where appropriate. The stringers were generally simply supported, and the shear connectors were not carried right to the ends of the girders. Sufficient shear connectors were provided at each end of the girders to develop the full strength of the composite section at the point where the full section was necessary to resist the bending stresses.

85. In relation to the pre-cambering of the light top flanges to the cross girders, after some experiments in the fabricating shop, these were pre-cambered by approximately $3 \mathrm{ft}$ in order to counteract the distortion caused by welding the shear connectors to the light fiange plates.

\section{REFERENCES}

1. German Standard DIN 1078, Verbundträger-Strassenbrücken 1955.

2. German Standard DIN 4239, Parts 1 \& 2, Verbundträger-Hochbau 1956.

3. YaN H. T. Composite Construction in Steel and Concrete. Indian Conc. J., June 1961, pp. 210-214, August 1961, pp. 310-313, September 1961, pp. 349-354. 